\title{
Knowledge and Attitude Regarding Drugs and Cosmetic Use among Pregnant Women Attending Antenatal Clinic of a Tertiary Care Center
}

\author{
Anuradha Kunal Shah ${ }^{1, *}$, Annal Abhay Vaidya ${ }^{2}$
}

\begin{abstract}
Background: Inappropriate use of drugs and certain cosmetics can cause potential harm to the mother as well as the fetus. Good knowledge about drug use can help pregnant women make informed decisions. This study was conducted to assess the knowledge and attitude among pregnant women regarding the usage of drugs and cosmetics during pregnancy. Materials and Methods: This cross-sectional study was conducted in the antenatal clinic of a tertiary care centre from August to November 2018 in 384 randomly selected pregnant women. Data were collected using an interviewer-administered questionnaire. Data analysis was done using SPSS version 21.0. Results: Around $51.56 \%$ of pregnant women believed that drugs may have an effect on them or the fetus and $11.19 \%$ believed the same for cosmetics. More than half of them feel that drugs should mainly be avoided in the third trimester. Around 25\% of women believed that the irrational use of drugs could cause congenital anomalies in the fetus. About $58.07 \%$ of women were of the opinion that pregnancy requires the consumption of many drugs and $34.11 \%$ preferred to use alternative medicine during pregnancy. The primary source of information in majority of women was doctors followed by media. Around $32.03 \%$ of women had taken drugs outside a doctor's prescription during their pregnancy. A decrease in cosmetic use was reported by $4.94 \%$ women. Conclusion: The knowledge regarding the correct use of drugs and cosmetics during pregnancy is poor. The use of non-prescribed medications is high. Educational programs for women to increase their knowledge of the potential risks to them as well as the fetus are necessary.

Key words: Pregnancy, Knowledge, Drugs, Cosmetics, Antenatal care.
\end{abstract}

Anuradha Kunal Shah" ${ }^{1 *}$ Annal Abhay Vaidya ${ }^{2}$ 'Department of Community Medicine, Seth GS Medical College and KEM Hospital, Parel, Mumbai, Maharashtra, INDIA.

2Department of OBG, Seth GS Medical College and KEM Hospital, Parel, Mumbai, Maharashtra, INDIA.

\section{Correspondence}

Dr. Anuradha Kunal Shah Department of Community Medicine, Seth GS Medical College and KEM Hospital, Parel, Mumbai-400012, Maharashtra, INDIA.

Phone no: +919449564095

Email: anuradha.moha@gmail.com

History

- Submission Date: 21-01-2020

- Revised Date: 24-04-2020

- Accepted Date: 16-07-2020

DOI : 10.5530/ijmedph.2020.3.19

Article Available online

http://www.ijmedph.org/v10/i3

\section{Copyright}

(C) 2020 Phcog.Net. This is an openaccess article distributed under the terms of the Creative Commons Attribution 4.0 International license.

\section{INTRODUCTION}

Pregnancy is a physiological condition that may require the usage of medications for pregnancyinduced conditions and acute or chronic diseases. The usage of medications may be continuous or intermittent depending on the condition. The use of inappropriate drugs can cause potential harm to the mother as well as the fetus. ${ }^{1-3}$ There is also evidence that certain chemicals in cosmetic products are also potential teratogens. ${ }^{4-8}$ Only the medications prescribed by an obstetrician like vitamins, minerals and other supplements or medications to treat common symptoms during pregnancy should be taken. It is therefore of utmost importance that, prescription medications without the physician's prescription and over the counter medication is avoided in pregnancy. Good knowledge about drug use can help pregnant women make informed decisions. Fewer studies have been conducted in India regarding knowledge of pregnant women regarding the usage of drugs and cosmetics during pregnancy.
This study was therefore conducted with an objective to assess the knowledge and attitude among pregnant women regarding the usage of drugs and cosmetics during pregnancy. This information can be useful in providing health education or counselling during the antenatal sessions.

\section{MATERIALS AND METHODS}

This cross-sectional study was conducted in the antenatal clinic of a tertiary care centre in a metropolitan city from August to November 2018. At $95 \%$ Confidence interval, using the formula, $\mathrm{n}=\left(\mathrm{Z}_{1-\alpha / 2}\right)^{2} \mathrm{P}(1-\mathrm{P}) / \mathrm{d}^{2}$ with $\mathrm{P}=0.50$ and $\mathrm{d}=0.05$, we obtained a minimum sample size of 384 . $^{9}$ Pregnant women of 18 years and above were recruited using simple random sampling until the desired sample size was reached. Ethical approval was obtained from the Institutional Ethics Committee. Written informed consent was taken from all participants. Data collection was done using an intervieweradministered pre-validated, semi-structured
Cite this article : Shah AK, Vaidya AA. Knowledge and Attitude Regarding Drugs and Cosmetic use among Pregnant Women Attending Antenatal Clinic of a Tertiary Care Center. Int J Med Public Health. 2020;10(3):92-6. 
questionnaire in the local language. Data entry and analysis was done using SPSS version 21.0.

\section{RESULTS}

This cross-sectional study conducted in 384 pregnant women using a semi-structured questionnaire yielded the following results. The sociodemographic and personal profile of the study participants is presented in Table 1.

Knowledge regarding drug and cosmetic use (Table 2): In our study, 198 (51.56\%) pregnant women believed that drugs may have an effect on them or the fetus. This belief was significantly higher among older women $(p=0.03)$ and women of higher educational status $(p<0.0000 .1)$. Out of these, $72(18.75 \%$ of total) were able to name at least one drug which is harmful in pregnancy. Women residing in urban areas $(p=0.024)$ and with higher education status $(p<0.0000 .1)$ and socio-economic status $(p<0.0000 .1)$ had a significant association with this concept. Also, $43(11.19 \%)$ women believed that cosmetics may have an effect on them or the fetus. All of them also believe that not all cosmetics are harmful during pregnancy. Most of them believed that drugs should mainly be avoided in the third trimester $(214,55.72 \%)$, followed by second (93, $24.21 \%)$ and first trimester (77, $20.05 \%)$. Around 96 (25\%) women believed that the irrational use of drugs could cause congenital anomalies in the fetus. This belief was significantly higher among women with higher educational status $(p<0.0000 .1)$, employed in clerical and other office jobs $(p<0.0000 .1)$ and primigravida $(p=0.043)$. About $223(58.07)$ women were of the opinion that pregnancy requires the consumption of many drugs. This opinion was significantly associated with primigravida women $(p<0.0000 .1)$. Also, $131(34.11 \%)$ preferred to use alternative medicine during pregnancy.

Figure 1 shows source of information regarding drug and cosmetic use in current pregnancy Out of 384 women, 156 (40.63\%) women told that their source of information regarding drug and cosmetic use in pregnancy were doctors or health care providers, for 84 (21.88\%) women it was mother in law and other relatives and for the rest 144 (37.5\%) women it was internet or media. More than half of the women were of the opinion that doctors do not give enough time for advice regarding drug use in pregnancy $(253,65.88 \%)$.

Attitude regarding drug and cosmetic use: In this study, 123 (32.03\%) pregnant women said to have taken drugs outside a doctor's prescription during their pregnancy mostly for ailments like vomiting, rhinitis, fever and headache. Younger women $(p=0.0006)$ and primigravida $(p=0.001)$ were significantly associated with this attitude. The most common reasons for taking drugs outside prescription were non-serious nature of the illness $(61,49.59 \%)$, emergency $(44,35.77 \%)$ and prior knowledge about safety $(18,14.63 \%)$. More than half of the participants i.e. 254 $(66.14 \%)$ of them reported to an increase in drug usage in pregnancy (apart from supplements), 81 (21.09\%) reported a decrease in drug usage

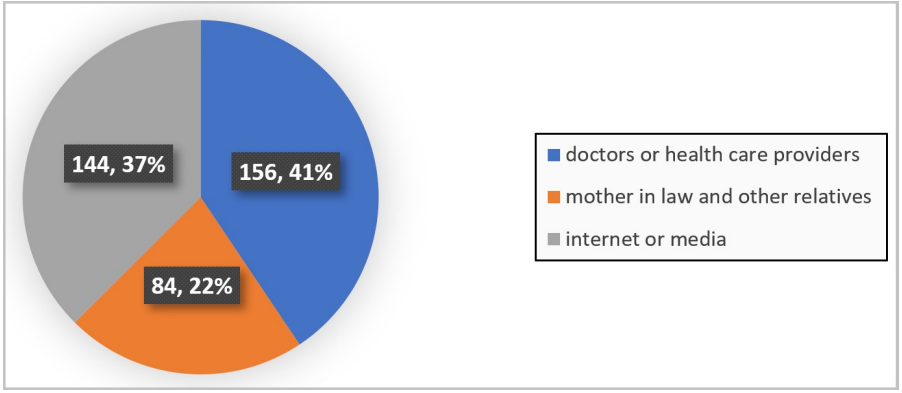

Figure 1: Source of information regarding drug use in current pregnancy $(n=384)$.
Table 1: Socio-demographic and personal profile of the study participants.

Characteristics

Number $(n=384) \quad$ Percentage

\begin{tabular}{|c|c|c|c|}
\hline \multirow[t]{3}{*}{ Age (in years) } & $18-25$ & 189 & 49.2 \\
\hline & $25-35$ & 169 & 44 \\
\hline & $>35$ & 26 & 6.7 \\
\hline \multirow{5}{*}{$\begin{array}{l}\text { Educational } \\
\text { Status }\end{array}$} & Illiterate & 42 & 10.9 \\
\hline & Primary & 123 & 32.03 \\
\hline & Secondary & 19 & 4.94 \\
\hline & Higher secondary & 111 & 28.9 \\
\hline & Graduation & 89 & 23.1 \\
\hline \multirow[t]{3}{*}{ Trimester } & First & 168 & 43.75 \\
\hline & Second & 133 & 34.63 \\
\hline & Third & 83 & 21.61 \\
\hline \multirow{3}{*}{$\begin{array}{l}\text { Place of } \\
\text { Residence }\end{array}$} & Rural & 29 & 7.5 \\
\hline & Urban & 199 & 51.8 \\
\hline & Sub -Urban & 156 & 40.6 \\
\hline \multirow[t]{5}{*}{ Occupation } & Housewife & 127 & 33.07 \\
\hline & Domestic help & 63 & 16.4 \\
\hline & Cook (noun) & 55 & 14.32 \\
\hline & Clerical work & 42 & 10.93 \\
\hline & Others & 97 & 25.26 \\
\hline \multirow[t]{2}{*}{ Parity } & Primigravida & 166 & 43.22 \\
\hline & Multigravida & 218 & 56.77 \\
\hline \multirow{2}{*}{$\begin{array}{l}\text { History of Child } \\
\text { Birth with any } \\
\text { Congenital } \\
\text { abnormality }\end{array}$} & Yes & 3 & 0.78 \\
\hline & No & 381 & 99.2 \\
\hline \multirow{5}{*}{$\begin{array}{l}\text { Socio-economic } \\
\text { Status (SES) } \\
\text { (Modified } \\
\text { BG Prasad } \\
\text { classification) }\end{array}$} & Lower & 31 & 8.07 \\
\hline & Lower middle & 99 & 25.78 \\
\hline & Middle & 151 & 39.32 \\
\hline & Upper middle & 69 & 17.96 \\
\hline & Upper & 34 & 8.85 \\
\hline \multirow{3}{*}{$\begin{array}{l}\text { Chronic illness } \\
\text { (Diabetes, } \\
\text { Epilepsy or } \\
\text { Hypertension) }\end{array}$} & Yes & 2 & 0.52 \\
\hline & No & 382 & 99.47 \\
\hline & & & \\
\hline \multirow{3}{*}{$\begin{array}{l}\text { No. of } \\
\text { medications } \\
\text { in current } \\
\text { pregnancy } \\
\text { (apart from } \\
\text { supplements) }\end{array}$} & $\leq 1$ & 187 & 48.69 \\
\hline & $1-2$ & 111 & 28.90 \\
\hline & $>2$ & 86 & 22.39 \\
\hline
\end{tabular}

and rest were unsure. A decrease in cosmetic use was reported by 19 (4.94\%) women. This attitude was significantly associated with higher education $(p=0.014)$ and socio-economic status (SES) $(p<0.0000 .1)$.

\section{DISCUSSION}

Use of medications with or without a physician's prescription or over the counter medications during pregnancy is showing an increasing trend. ${ }^{10,11}$ This cross-sectional study was conducted in 384 pregnant women with an objective to assess the knowledge and attitude among 


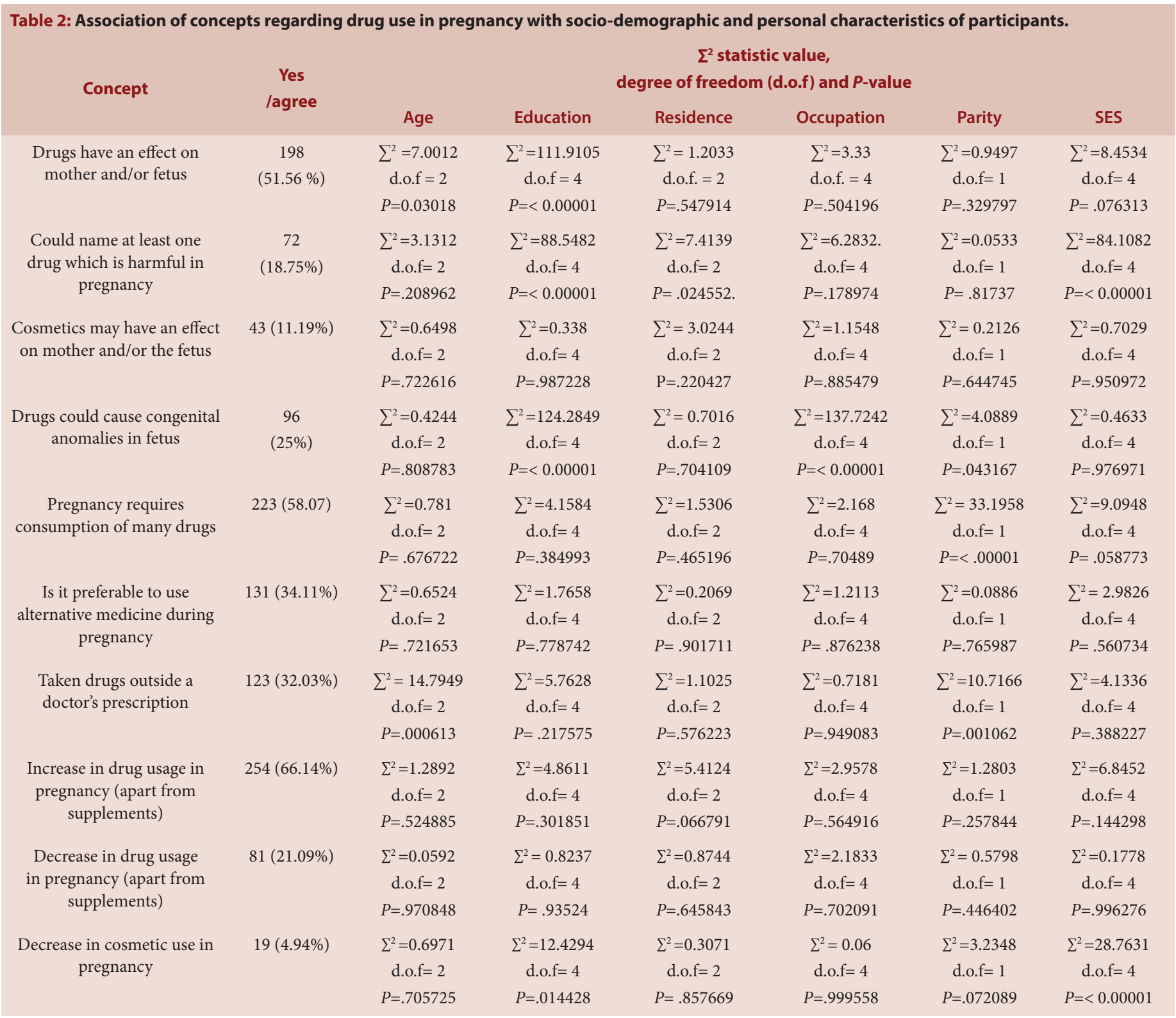

[Note: $P<0.05$ is considered significant, SES $=$ Socio-economic Status, $\Sigma^{2}=$ Chi- square statistic value]

pregnant women regarding the usage of drugs and cosmetics during pregnancy.

In our study, $51.56 \%$ of the pregnant women believed that drugs may have an effect on them or the fetus and $25 \%$ believed that irrational drugs could cause congenital anomalies in the fetus. These findings are similar to a study by Dureja et al. where $40 \%$ of women believed that drugs have an effect on the fetus but only $22.4 \%$ believed that irrational use can cause congenital anomalies in the fetus. ${ }^{12}$ Gopinath et al. reported that $17 \%$ of women believed that medications were responsible for congenital abnormalities of their newborn. ${ }^{13}$ However, in a study in Italy a higher number of women i.e. $81.15 \%$ knew about the possibility of harm to the fetus due to medications used in pregnancy. ${ }^{14}$ This higher rate could be attributed to higher education status and awareness. We also found a significant association between higher educational status and knowledge regarding drug use in pregnancy. Knowledge regarding congenital anomalies was additionally associated with employment type i.e. those employed in clerical and other office jobs. These findings are similar to a study by Zaki et al. where the education level and type of employment were significantly associated with knowledge of pregnant women regarding drugs. ${ }^{15}$

Around $19 \%$ of women in our study were able to name at least one drug which is harmful in pregnancy. Women residing in urban areas and with higher education and socio-economic status were better at it. Gopinath et al. also report that residents of urban areas have more risk awareness about drug usage in pregnancy. ${ }^{13}$ Kamuhabwa et al. reported that $31.5 \%$ of women were able to mention certain drugs harmful during pregnancy. ${ }^{16}$ In contrast, two studies have reported a very less proportion of women (1-4\%) who could list drugs harmful during pregnancy. ${ }^{12,13}$

Women in our study believed that drugs should mainly be avoided in the third trimester, followed by the second and first trimester. In contrast to this, more than half of the participants in Eldalo et al. ${ }^{17}$ and almost all in Zaki et al..$^{15}$ knew that drugs should mainly be avoided in the first trimester. 
More than half of the women (58.07\%) in our study were of the opinion that pregnancy requires the consumption of many drugs. This opinion was significantly higher in primigravida women. More than half of the participants $(66.14 \%)$ reported an increase in drug usage in pregnancy. Also, $34.11 \%$ preferred to use alternative medicine during pregnancy. Similar findings were reported by Gopinath et al. and Dureja et al. where $30 \%$ and $66.6 \%$ of women respectively believed natural remedies/ alternative medicines can be used in pregnancy. They also reported that around $60 \%$ of the women thought they were prescribed many medications by the physicians. ${ }^{12,13}$

Around $11 \%$ of women in our study believed that cosmetics may have an effect on them or the fetus but, all of them also believe that not all cosmetics are harmful during pregnancy. A decrease in cosmetic use during pregnancy was reported by $4.94 \%$ women. Dureja et al. reported $23.4 \%$ of women had knowledge of the effect of the use of cosmetics during pregnancy which is higher than that of our findings. ${ }^{12}$ A study by Marie et al. showed that few women stopped cosmetic use during pregnancy except for nail polish and almost half of them considered that there is no risk in the use of cosmetics during pregnancy. ${ }^{18}$

We also found that $32.03 \%$ of pregnant women said to have taken drugs outside a doctor's prescription during their pregnancy mostly for ailments like vomiting, rhinitis, fever and headache. Younger women and primigravida were significantly associated with this attitude. Similarly, in a study by Navrao et al. $43.9 \%$ had used drugs without physician's advice. The most frequent reasons were fever/common cold symptoms (32.6\%), headache/migraine (29.5\%), digestive disorders (18.2\%) and nerve pain (15.5\%). ${ }^{14}$ Zaki et al. reported that most commonly used drugs were paracetamol and vitamins (13.2\%), antibiotics (2.6\%), herbal remedies $(4.6 \%)$ and medications to treat nausea and vomiting in pregnancy (2.6\%), NSAIDs, anti-histaminic and heartburn medications (1.3\%). ${ }^{15} \mathrm{In}$ contrast, $96 \%$ women did not take drugs without physician's advice in a study by Eldalo et al. ${ }^{17}$ In our study, most common reasons for taking drugs outside prescription were non-serious nature of illness (49.59\%), emergency (35.77\%) and prior knowledge about safety (14.63\%). Navrao et al. reported that the main reasons were a not serious disease (47\%), advice/ information by pharmacists $(29.7 \%)$, prior knowledge about safety in pregnancy (14.6\%) and emergency care (13.5\%). ${ }^{14}$ In $40.63 \%$ of women, the primary source of information regarding drug and cosmetic use in pregnancy were doctors or health care providers, followed by internet or media and mother in law and other relatives. In other studies conducted worldwide, the proportion of women obtaining information doctors is more than $60 \%{ }^{12,14,15,17}$ In a study by Eldalo et al. $60.2 \%$ obtained this information from physicians, $34.4 \%$ from pharmacists and only $1.4 \%$ from media. ${ }^{17}$ Navrao et al. reported that $75 \%$ obtained information from physicians, followed by the internet in $47 \%$ and pharmacists in $14.7 \%^{14}$ Zaki et al. reported that gynecologists $(58.1 \%)$ followed by a general practitioner (13\%), pharmacist (11\%) and lastly the media, family and friends as well as the internet (10\%) were primary sources. ${ }^{15}$ Dureja et al. also reported similar findings. ${ }^{12}$

We found that in our study around $66 \%$ of the women were of the opinion that doctors do not give enough time for advice regarding drug use in pregnancy and these findings are also corroborated by many studies. ${ }^{12,15}$ However, in contrast to our findings, Eldalo et al. reported that $71 \%$ of women thought that they received complete information about drugs from their physicians.

\section{CONCLUSION}

The knowledge regarding the use of drugs and cosmetics among pregnant women is poor. Less than half of them have correct knowledge regarding the effects of drugs and cosmetics on the health of mother and fetus. The use of over the counter medication or non-prescribed medications among pregnant women is also high. The primary source of information in the majority of them is doctors. The results provide a good opportunity to include educational programs for women and increase their knowledge of the potential risks to them as well as the fetus in order to reduce self-medication.

\section{ACKNOWLEDGEMENT}

The authors would like to thank Lt. Dr. Ratnendra Shinde, Ex- Head of the Departments, Department of Community Medicine, Seth G S Medical College.

\section{CONFLICT OF INTEREST}

The authors declare that they have no conflicts of interest

\section{ABBREVIATIONS}

SES: Socio-economic status; $\Sigma^{2}$ : Chi- square statistic value.

\section{REFERENCES}

1. Cabbage LA, Neal JL. Over-the-counter medications and pregnancy. Nurse Pract. 2011;36(6):22-8. Available from: http://www.ncbi.nlm.nih.gov/ pubmed/21558979

2. DeSantis M, Straface G, Carducci B, Cavaliere AF, DeSantis L, Lucchese A, et al. Risk of drug-induced congenital defects. Eur J Obstet Gynecol Reprod Biol. 2004;117(1):10-9. Available from: http://www.ncbi.nlm.nih.gov/ pubmed/15474237

3. Bánhidy F, Lowry RB, Czeizel AE. Risk and Benefit of Drug Use During Pregnancy. International Journal of Medical Sciences. 2005;2(3):100. Available from: www.medsci.org

4. Braun JM, Just AC, Williams PL, Smith KW, Calafat AM, Hauser R. Personal care product use and urinary phthalate metabolite and paraben concentrations during pregnancy among women from a fertility clinic. J Expo Sci Environ Epidemiol. 2014;24(5):459-66. Available from: http://www.ncbi.nlm.nih.gov/ pubmed/24149971

5. Couto AC, Ferreira JD, Rosa ACS, Pombo-de-Oliveira MS, Koifman S. Brazilian Collaborative Study Group of Infant Acute Leukemia. Pregnancy, maternal exposure to hair dyes and hair straightening cosmetics and early age leukemia. Chem Biol Interact. 2013;205(1):46-52. Available from: http://www.ncbi.nlm.nih. gov/pubmed/23747844

6. Dehvari M, Ghaneian MT, Morowatisharifabad MA, Karimi M, Jasemizad T. Knowledge, Attitudes and Practice of Women About Adverse Effects of Cosmetics in Yazd City, Iran. Heal Scope. 2018;7(1):68257. Available from: http:// jhealthscope.com/en/articles/68257.html

7. Bozzo P, Chua-Gocheco A, Einarson A. Safety of skin care products during pregnancy. Can Fam Physician. 2011;57(6):665. Available from: http://www.ncbi. nlm.nih.gov/pubmed/21673209

8. Trivedi MKM, Kroumpouzos G, Murase JEJJEJ. A review of the safety of cosmetic procedures during pregnancy and lactation. Int $\mathrm{J}$ Women's Dermatology. 2017;3(1):6-10. Available from: https://linkinghub.elsevier.com/retrieve/pii/ S2352647517300059

9. Lemeshow S, JrHosmer DW, Klar J, Lwanga SK. Adequacy of Sample Size in Health Studies. $1^{\text {st }}$ ed. World Health Organisation. John Wiley and Sons Ltd. 1990;247. Available from: http://apps.who.int/iris/bitstream/10665/41607/1/0471925179_eng.pdf?ua=1

10. Smolina K, Hanley GE, Mintzes B, Oberlander TF, Morgan S. Trends and Determinants of Prescription Drug use during Pregnancy and Postpartum in British Columbia. PLoS One. 2015;10(5):128312. Available from: www.cihr-irsc. gc.ca/e/193.html

11. Mitchell AA, Gilboa SM, Werler MM, Kelley KE, Louik C, Hernández-Díaz S Medication use during Pregnancy, with Particular Focus on Prescription Drugs: 1976-2008. Am J Obs Gynecol. 2011;205(1):51.e1-8. [cited 2019 Aug 11]. Available from: https://www.ncbi.nlm.nih.gov/pmc/articles/PMC3793635/pdf/nihms481903.pdf

12. Dureja S, Kaur M, Bhandari V, Singh N, Singh J, Sharma R. Awareness among pregnant women regarding the use and safety of drugs during pregnancy in the state of Punjab: A cross-sectional observational study. Int J Med Sci Public Heal. 2019; 8(6):478-81.

13. Gopinath C, Giri RSD, Suresh G, Guru PD, Madhan MRM. Assessment of Pregnant Women Knowledge on Medication. World J Pharm Res. 2015;4(12):1266 76. Available from: www.wjpr.net

14. Navaro M, Vezzosi L, Santagati G, Angelillo IF, Group CW. Knowledge, attitudes and practice regarding medication use in pregnant women in Southern Italy. PLoS One. 2018;13(6):e0198618. Available from: https://dx.plos.org/10.1371/ journal.pone.0198618 
15. Zaki NM, Albarraq AA. Use, attitudes and knowledge of medications among pregnant women: A Saudi study. Saudi Pharm J. 2014;22(5):419-28. Available from: http://www.ncbi.nlm.nih.gov/pubmed/25473330

16. Kamuhabwa A, Jalal R. Drug use in pregnancy: Knowledge of drug dispensers and pregnant women in Dar es Salaam, Tanzania. Indian J Pharmacol. 2011;43(3):345. Available from: http://www.ncbi.nlm.nih.gov/pubmed/21713045
17. Eldalo A, Siraj N, Yousif M. Pregnant Women's Awareness and Perception About Medicines. Lat Am J Pharm. 2015;34(5):869-74.

18. Marie C, Cabut S, Vendittelli F, Sauvant-Rochat MP. Changes in Cosmetics Use during Pregnancy and Risk Perception by Women. Int J Environ Res Public Health. 2016;13(4):383. Available from: http://www.mdpi.com/1660$4601 / 13 / 4 / 383$

Cite this article : Shah AK, Vaidya AA. Knowledge and Attitude Regarding Drugs and Cosmetic use among Pregnant Women Attending Antenatal Clinic of a Tertiary Care Center. Int J Med Public Health. 2020;10(3):92-6. 